\title{
Barriers to Women's Pap Smear Testing and Related Risk Factors in Turkey
}

\author{
Seyhan Cankaya (D, Gamze Yuksel (D) \\ Selcuk University, Faculty of Health Sciences, Department of Midwifery, Konya, Turkey. \\ Correspondence Author: Seyhan Cankaya \\ E-mail: seyhancankaya@selcuk.edu.tr \\ Received: 11.11.2019 Accepted: 03.07.2020
}

\begin{abstract}
Objective: This study aimed to identify the barriers to women's Pap smear testing and related risk factors.

Methods: In this descriptive and cross-sectional study, 294 women were included by stratified random sampling. The General Information Questionnaire, The Self-Efficacy Scale, The Health Belief Model Scale for Cervical Cancer, and the Pap Smear Test were used.

Results: About half of the women (47.6\%) had a Pap smear test in their lifetime. Residing in a village/non-provincial district $(O R=0.412)$, not having a Pap smear test because family members/friends did not have one $(O R=7.752)$, having high Barriers subscale scores $(O R=1.053)$, and having lower self-efficacy levels $(O R=0.951)$ were found to be risk factors for not having a Pap smear test. In addition, not knowing the symptoms of cervical cancer, believing that the cervical cancer is a non-treatable condition, expecting to experience vaginal infection, not being able to get permission from her husband, and considering the test as embarrassing were found among the barriers $(p<0.005)$.

Conclusion: A well designed health education program focusing on cervical cancer and the benefits of screening would increase awareness, especially among women with a high educational attainment status. Public health nurses and midwives should provide health educations considering the local cultural environment. To improve access to health services, mobile health services need to be developed, and in hospitals, routine Pap smear test health educations should be conducted and guidance should be provided.
\end{abstract}

Keywords: Cervical cancer, screening, barriers, self-efficacy, health belief model, Pap smear test.

\section{INTRODUCTION}

Cervical cancer is globally an important cause of morbidity and mortality in women of all ages $(1,2)$. In Turkey, cervical cancer incidence increases at the age of 40 and over (10.5 per 100.000), and its highest incidence rate (15.7 per 100.000) is seen in 65-70 year-old women (3). Per the recommendation of the World Health Organization (WHO), women in Turkey in the age range of 30-65 years have been screened every 5 years since 1992 with the Pap (Papanicolaou) test (3). Despite this effort, the rate of Pap smear test in Turkey is not at a desired level. According to a report by the Turkish Statistical Institute (TSI), only $30 \%$ of the women in the age range of 25-65 had a Pap smear test (4). The rate of having a Pap smear test in the previous year in women over the age of 15 years in Turkey was reported to be $10.9 \%$ and the rate of those who had never had a Pap smear test before was $69.3 \%$ (5). This rate is expected to be much higher considering the facts that, in the Turkish health care system, Pap smear tests are performed at a very low cost in urban and rural areas, and even they are performed free of charge in Cancer Early
Diagnosis, Screening and Education Centers. However, in both national health statistics and surveys conducted in different geographical areas of the country, the rate of having a Pap smear test is very low $(4,6,7)$. In Turkey, studies investigating the reasons why women do not participate in cervical cancer screenings and why they do not have a Pap smear test are very limited and it is very important to find out the barriers to their participation in screening tests. In international studies, barriers to women's having a Pap smear test have been cited as lack of knowledge, religious beliefs, embarrassment, difficulty in access, the fear of a positive result, no health insurance, not having time, and the gender of the healthcare provider (8-10). In a study conducted in Texas, USA involving 524 women, the following barriers were cited: cost (61.6\%), fear of a positive result (53.1\%), worry $(38.7 \%)$, embarrassment $(25.6 \%)$, expectation of pain $(23.6 \%)$, male obstetrician (19.7\%), lack of knowledge (18.8\%), language (18.3\%), other health problems (16.5\%), neglecting to make an appointment (14.9\%), and not allocating time (13\%) (11). 
In another study conducted in Nigeria, the following factors were reported: the gender of the healthcare provider, the fear of a positive result, the fear of catching a disease at the hospital, discomfort during screening, not being aware of the screening programs, not caring much about cervical cancer, and the need for their husband's approval before screening (9). In order to reduce the incidence of cervical cancer, it is important to understand the perceived structural and personal barriers, misconceptions, and socio-cultural differences in the population in having cervical screening tests. The aim of this study was to identify the barriers to women's having a Pap smear test and related risk factors.

The questions addressed in the study were:

1. Do sociodemographic characteristics of women affect the rate of having a Pap smear test?

2. Is there a relationship between women's having a Pap smear test and their Health Belief Model Scale for Cervical Cancer-Barriers subdomain and Pap Smear Test scores?

3. Do the women's self-efficacy levels affect the rate of having a Pap smear test?

4. Do cultural factors affect the rate of having a cervical screening test?

\section{METHODS}

\subsection{Design}

The study was designed as descriptive and cross-sectional.

\subsection{Study Setting}

The research was carried out at Family Health Centers (FHCs) located in Konya, a province in the Central Anatolia Region of Turkey. There are three metropolitan districts of Konya, namely, Karatay, Meram, and Selcuklu. There are 23, 25, and 24 FHSs in these districts, respectively, with a total of 72 FHSs in the province. Since the women living in these districts have sociodemographic and lifestyle differences and to ensure heterogeneity in the study, women from 3 districts were included in the study. One FHS from each district was randomly selected: FHC-15 from Karatay, FHC-5 from Selcuklu, and FHC-25 from Meram.

\subsection{Study Population, Sample Size, and Sampling Strategy}

The universe of the study was all $\geq 18$ year-old women who were married or living with a partner and presented to the selected FHCs between 1 February and 1 May 2019. Sample size of the study was calculated using an online tool: A-priori Sample Size Calculator for Multiple Regression (12). The sample size was calculated based on 2 main variables and 21 observed variables, with an effect size of 0.10 (medium), statistical power of 0.90 , and $\alpha$ probability of error of 0.05 . The minimum required sample size was calculated as 294 using the online calculator (13). During the study period, 350 women were invited to participate, but 56 women rejected to take part due to such reasons as infants' crying, breastfeeding, disapproval of the partner/husband, and lack of time. Therefore, the study was completed with 294 women, who agreed to participate in the study and filled out the forms completely. For this descriptive, cross-sectional research, a total of 294 women were included by means of convenience sampling. The inclusion criteria were being women, being at an age of $\geq 18$ years, having an active sexual life, being literate, being able to speak Turkish, and being volunteer. There was no upper age limit in the participation criteria and women who were in premenopausal or menopausal women were included in the study. Exclusion criteria were being virgin, pregnant, being in the postpartum period, having been diagnosed with cervical preinvasive lesion or cervical cancer, having a mental problem, having an inactive sexual life, and not being able to speak Turkish.

\subsection{Pilot Study}

To pretest the items in the data collection tools, the tools were administered in 5 women from each $\mathrm{FHC}$ and the item with which the women had difficulty in understanding was revised. The answers given by these women were not included in statistical analyses.

\subsection{Data Collection}

We used a well-structured self-administered questionnaire to collect the data. All participants who properly completed the questionnaire were included in the study. The questionnaire had three sections and took about 15 minutes to complete. The data were collected by the researchers by face-to-face interviews. Women who were willing to participate in the study were asked to fill in the questionnaires in a private room in the FHC. The General Information Questionnaire, the SelfEfficacy Scale, the Cervical Cancer and Pap Smear Test Health Belief Model-Barriers Subscale were used for data collection regarding the women's socio-demographic features and the barriers to the women's having a cervical screening test.

\subsection{Measures}

2.6.1. The general information questionnaire: This questionnaire was developed by the researcher using the literature. It consists of two parts as 'socio-demographic items' and 'items regarding the barriers to the women's having a cervical test'.

Socio-demographic items: This part comprises 13 items about the educational level, marital status, place of residence, employment status, health insurance status, income level, family type, year of marriage, number of children, chronic disease status (hypertension, diabetes mellitus, etc.), family/ individual history of cervical cancer, age, and the age of menarche $(9-11,14)$. 
Items regarding the barriers to the women's having a cervical test: This section comprises 9 items, namely, “(1) I don't know the symptoms and indications of cervical cancer, (2) I believe that cervical cancer is not a treatable disease, (3) I don't want to have a Pap smear test because of others' negative comments about it (4) I think that I'll get vaginal infection after the Pap smear test, (5) Because my husband/partner would not allow me to have a Pap smear test, (6) I cannot have a Pap smear test because I cannot afford it, (7) I don't have a Pap smear test because my family members/friends do not have it, (8) I think that Pap smear test is embarrassing, and (9) My religion would not allow me to have a Pap smear test" $(10,11,14,15)$.

2.6.2. The self-efficacy scale: This scale is used to assess women's self-efficacy perceptions regarding the early diagnosis of breast and cervical cancer. The scale was developed by Lechner et al. and reliability and validity studies of the Turkish version of the scale were conducted by Beser et al. Cronbach's Alpha coefficient of the scale is $0.90(16,17)$. The scale comprises seven 7-point Likert-type items. The total score of the scale ranges between -21 and +21 . The higher score indicates better self-efficacy perception regarding the improvement of a specific behavior. Cronbach's Alpha internal consistency coefficient of the Self-Efficacy Scale in the present study was found as 0.88 .

2.6.3. The health belief model scale for cervical cancer and the pap smear test: The scale was first developed by Champion et al. in 2004 to assess breast cancer screening and the adaptation of the scale for cervical cancer screening was carried out by Guvenc et al in 2008 (18). The adapted version of the scale assesses the effects of the women's health beliefs about cervical cancer and Pap smear test on the rate of having a Pap smear test. Cronbach's Alpha internal consistency coefficient of the scale was reported as 0.62 0.86 (18). Cronbach's Alpha internal consistency coefficient for Pap smear barrier perceptions (14 items) was found as 0.82 . The scale comprises 35 items (5-point Likert-type) in 5 subscales. Responses receive points between 1 and 5 . Each subscale is evaluated internally. The total score of the Barriers subscale ranges between 14 and 70 . Higher scores indicate a higher perception of the barriers. Cronbach's Alpha internal consistency coefficient in the present study was found as 0.80 .

\subsection{Ethical Approval}

At the beginning of the research, research ethics committee approval was granted by the Faculty of Health Sciences of Selcuk University (Ethics permit no: 34/2019). Institutional permission was obtained from the Health Directorate of Konya Province (10.12.2018, 94723667-806.01.03). The primary purpose of the research was explained to all participants. All women involved in this study signed an informed consent form. Furthermore, all the information related to the participants was kept strictly confidential.

\subsection{Data Analysis}

The statistical package program of SPSS 20.0 for Windows (SPSS Inc., Chicago, IL, USA) was used to analyze the data. Because all skewness and Kurtosis values of all scales were found between -1.50 and +1.50 , independent samples $t$-tests were carried out (19). As descriptive statistical values, numbers, percentages, means, and standard deviations (SD) were used. A Chi-square test was used in the comparison of the rate of having a Pap smear test and their sociodemographic and obstetric characteristics and in comparing some of the factors in barriers to having a Pap smear test.

Educational status, marital status, the place of the longest residence, employment status, health insurance status, perceived income level, family type, year of marriage, the number of children, chronic disease status, family/individual history of cervical cancer, age, Self-Efficacy scores, The Health Belief Model Scale for Cervical Cancer and the Pap Smear Test - Barriers Subscale scores were treated as independent variables in bivariate analyses. As to the independent variables found significant after performing the bivariate analyses, variables, such as women's educational status ( $1=$ junior high school and under and $0=$ senior high school and over), the longest place of residence ( 1 = village/country, and $0=$ city), family type ( 1 = extended family, and $0=$ nuclear family), the number of children ( $1=2$ and under, and $0=3$ and over), the chronic disease status ( $0=$ no, and $1=$ yes), age, Self-Efficacy Scale Scores, and The Health Belief Model Scale for Cervical Cancer and the Pap Smear Test - Barriers Subscale scores were included in the logistic regression analysis. Logistic regression analysis with the Backward method was conducted to identify the risk factors causing the barriers to having a Pap smear test. Not having a Pap smear test was assumed as the dependent variable. The assessment was based on having a Pap smear test ( $1=$ no) and not ( $0=y e s$ ). In the study, two tailed tests were used, and significance was accepted as $p<0.05$.

\section{RESULTS}

The mean (SD) age of the women was 39.9 (10.3) years with a mean (SD) marriage year of 18.4 (11.6) years. The mean (SD) age of menarche was found to be 13.4 (1.2) and the mean (SD) number of children they had was 2.4 (1.2). Of the women, $47.6 \%(n=140)$ had at least one Pap smear test in their lifetime and $24.8 \%(n=73)$ had the test within the previous 12 months.

Those who were graduates of high school and above ( $p=$ $0.014)$, those living in villages/districts $(p=0.001)$, those living in extended families $(p=0.018)$, those with a marriage year of 10 years or less $(p=0.000)$, those with 2 children or less $(p=0.009)$, those with no chronic disease $(p=0.004)$, younger women $(p=0.000)$, those with lower Self-Efficacy Score $(p=0.000)$, and those with higher Health Belief Model Scale for Cervical Cancer and the Pap Smear Test - Barriers Subscale scores $(p=0.000)$ tended not to have a Pap smear test with a significant difference (Table 1 ). 
Table 1. Women's Sociodemographic and Obstetric Characteristics and the Rate of Having a Pap Smear Test $(n=294)$

\begin{tabular}{|c|c|c|c|c|}
\hline \multirow{3}{*}{ Characteristics } & \multicolumn{2}{|c|}{$\begin{array}{l}\text { Rate of having a Pap } \\
\text { smear test }\end{array}$} & \multirow{3}{*}{$t / x^{2}$} & \multirow{3}{*}{$P$ value } \\
\hline & \multirow{2}{*}{$\begin{array}{l}\text { Yes } \\
\text { n (\%) }\end{array}$} & \multirow{2}{*}{$\begin{array}{l}\text { No } \\
\text { n (\%) }\end{array}$} & & \\
\hline & & & & \\
\hline \multicolumn{5}{|l|}{ Educational level } \\
\hline High school and over & $96(53.3)$ & $84(46.7)$ & \multirow[t]{2}{*}{$6.077^{a}$} & \multirow[t]{2}{*}{0.014} \\
\hline Middle school and under & $44(38.6)$ & $70(61.4)$ & & \\
\hline \multicolumn{5}{|l|}{ Marital status } \\
\hline Married & $135(48.7)$ & $142(51.3)$ & \multirow[t]{2}{*}{$2.398^{\mathrm{a}}$} & \multirow[t]{2}{*}{0.121} \\
\hline Widowed & $5(29.4)$ & $12(70.6)$ & & \\
\hline \multicolumn{5}{|l|}{ Place of residence } \\
\hline Village/district & $38(34.5)$ & $72(65.5)$ & \multirow[t]{2}{*}{$12.044^{\mathrm{a}}$} & \multirow[t]{2}{*}{0.001} \\
\hline City & $102(55.4)$ & $82(44.6)$ & & \\
\hline \multicolumn{5}{|l|}{ Employment status } \\
\hline Employed & $35(50.7)$ & $34(49.3)$ & \multirow[t]{2}{*}{$0.349^{a}$} & \multirow[t]{2}{*}{0.555} \\
\hline Unemployed/housewife & $105(46.7)$ & $120(53.3)$ & & \\
\hline \multicolumn{5}{|l|}{ Health Insurance } \\
\hline Yes & $133(48.5)$ & $141(51.5)$ & \multirow[t]{2}{*}{$1.370^{\mathrm{a}}$} & \multirow[t]{2}{*}{0.242} \\
\hline No & $7(35)$ & $13(65)$ & & \\
\hline \multicolumn{5}{|l|}{ Perceived Income Level } \\
\hline Poor & $31(53.4)$ & $27(46.6)$ & \multirow[t]{2}{*}{$0.984^{\mathrm{a}}$} & \multirow[t]{2}{*}{0.321} \\
\hline Moderate/good & $109(46.2)$ & $127(53.8)$ & & \\
\hline \multicolumn{5}{|l|}{ Family Type } \\
\hline Nuclear Family & $123(50.8)$ & $119(49.2)$ & \multirow[t]{2}{*}{$5.643^{\mathrm{a}}$} & \multirow[t]{2}{*}{0.018} \\
\hline Extended Family & $17(32.7)$ & $35(67.3)$ & & \\
\hline Year of Marriage & & & & \\
\hline 10 year and less & $18(20.9)$ & $68(79.1)$ & $34.713^{\mathrm{a}}$ & 0.000 \\
\hline 11 year and more & $122(58.7)$ & $86(41.3)$ & & \\
\hline Number of Children & & & & \\
\hline 2 and under & $65(40.6)$ & 95 (59.4) & $6.884^{\mathrm{a}}$ & 0.009 \\
\hline 3 and over & $75(56)$ & $59(44)$ & & \\
\hline Chronic Disease Status & & & & \\
\hline Yes & $49(61.2)$ & $31(38.8)$ & $8.187^{\mathrm{a}}$ & 0.004 \\
\hline No & $91(42.5)$ & $123(57.5)$ & & \\
\hline $\begin{array}{l}\text { Family/individual history } \\
\text { of cervical cancer }\end{array}$ & & & & \\
\hline Yes & $10(58.8)$ & $7(41.2)$ & $0.908^{\mathrm{a}}$ & 0.341 \\
\hline No & $130(46.9)$ & $147(53.1)$ & & \\
\hline Age (mean and SD) & $42.6(7.9)$ & $\begin{array}{ll}3 & 7 \\
(11.5)\end{array} \cdot 4$ & $4.546^{b}$ & 0.000 \\
\hline $\begin{array}{l}\text { The Self-Efficacy Scale } \\
\text { (mean and SD) }\end{array}$ & $5.7(9.3)$ & $0.3(9.2)$ & $4.982^{b}$ & 0.000 \\
\hline $\begin{array}{l}\text { The Health Belief Model } \\
\text { Scale for Cervical Cancer } \\
\text { and the Pap Smear Test- } \\
\text { Barriers Subscale (mean } \\
\text { and SD) }\end{array}$ & 34.7 (9.1) & $39.5(8.7)$ & $-4.529^{b}$ & 0.000 \\
\hline & & & & \\
\hline
\end{tabular}

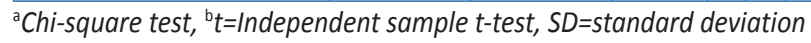

In terms of barriers to having a Pap smear test in relation with the characteristics of the Turkish society, those who do not know the symptoms and indications of cervical cancer $(p=0.028)$, those who believe that cervical cancer is not a treatable disease $(p=0.014)$, those who believe that they would experience vaginal infection after the test $(p=0.019)$, those who cannot get permission from their husbands $(p=$ 0.000 ), those who do not have the test because their families or friends do not have it $(p=0.001)$, and those who believe that the test is embarrassing $(p=0.000)$ were had a tendency to not having the test with a significant difference (Table 2).

Table 2. Factors Causing the Barriers to Having a Pap Smear Test

\begin{tabular}{|c|c|c|c|c|}
\hline \multirow[t]{3}{*}{ Factors } & \multicolumn{2}{|c|}{$\begin{array}{l}\text { The rate of having a } \\
\text { Pap smear test }\end{array}$} & \multirow[b]{3}{*}{$x^{2}$} & \multirow[b]{3}{*}{ P-valu } \\
\hline & Yes & No & & \\
\hline & $n(\%)$ & $n(\%)$ & & \\
\hline \multicolumn{5}{|l|}{$\begin{array}{l}\text { I don't know the symptoms } \\
\text { and indicators of cervical } \\
\text { cancer }\end{array}$} \\
\hline Yes & $89(43.4)$ & $116(56.6)$ & \multirow[t]{2}{*}{4.799} & \multirow[t]{2}{*}{0.028} \\
\hline No & 51 (57.3) & $38(42.7)$ & & \\
\hline \multicolumn{5}{|l|}{$\begin{array}{l}\text { I believe that cervical cancer } \\
\text { cannot be fully treated }\end{array}$} \\
\hline Yes & $89(43)$ & $118(57)$ & \multirow[t]{2}{*}{5.996} & \multirow[t]{2}{*}{0.014} \\
\hline No & $51(58.6)$ & 36 (41.4) & & \\
\hline \multicolumn{5}{|l|}{$\begin{array}{l}\text { I don't want to have the test } \\
\text { because I heard negative } \\
\text { comments about it }\end{array}$} \\
\hline Yes & $62(48.1)$ & 67 (51.9) & \multirow[t]{2}{*}{0.018} & \multirow[t]{2}{*}{0.893} \\
\hline No & $78(47.3)$ & 87 (52.7) & & \\
\hline \multicolumn{5}{|l|}{$\begin{array}{l}\text { I believe that I will have a } \\
\text { vaginal infection after the } \\
\text { Pap smear test }\end{array}$} \\
\hline Yes & 45 (39.1) & 70 (60.9) & \multirow[t]{2}{*}{5.456} & \multirow[t]{2}{*}{0.019} \\
\hline No & $95(53.1)$ & 84 (46.9) & & \\
\hline \multicolumn{5}{|l|}{$\begin{array}{l}\text { I cannot get permission from } \\
\text { my husband }\end{array}$} \\
\hline Yes & 41 (34.7) & 77 (65.3) & \multirow[t]{2}{*}{13.096} & \multirow[t]{2}{*}{0.000} \\
\hline No & $99(56.2)$ & 77 (43.8) & & \\
\hline \multicolumn{5}{|l|}{$\begin{array}{l}\text { I cannot have the test } \\
\text { because I don't have health } \\
\text { insurance }\end{array}$} \\
\hline Yes & $5(27.8)$ & $13(72.2)$ & \multirow[t]{2}{*}{3.026} & \multirow[t]{2}{*}{0.082} \\
\hline No & 135 (48.9) & 141 (51.1) & & \\
\hline \multicolumn{5}{|l|}{$\begin{array}{l}\text { I do not have the test because } \\
\text { my family or friends do not } \\
\text { have it }\end{array}$} \\
\hline Yes & $11(24.4)$ & $34(75.6)$ & \multirow[t]{2}{*}{11.440} & \multirow[t]{2}{*}{0.001} \\
\hline No & 129 (51.8) & $120(77.9)$ & & \\
\hline \multicolumn{5}{|l|}{$\begin{array}{l}\text { I think that Pap smear test is } \\
\text { embarrassing }\end{array}$} \\
\hline Yes & $12(24.5)$ & $37(75.5)$ & \multirow[t]{2}{*}{12.611} & \multirow[t]{2}{*}{0.000} \\
\hline No & $128(52.2)$ & $117(47.8)$ & & \\
\hline \multicolumn{5}{|l|}{$\begin{array}{l}\text { My religious beliefs would } \\
\text { not allow me to have a Pap } \\
\text { smear test }\end{array}$} \\
\hline Yes & $5(38.5)$ & 8 (61.5) & \multirow[t]{2}{*}{0.457} & \multirow[t]{2}{*}{0.499} \\
\hline No & $135(48)$ & $146(52)$ & & \\
\hline
\end{tabular}

Table 3 presents the results of our regression analyses. Risk factors causing a barrier to cervical cancer screening are: 
living in a village/non-metropolitan district (Odds Ratio $[\mathrm{OR}]=0.412,95 \%$ Confidence Interval $[\mathrm{Cl}]=0.227-0.747$ ), having family/friends not having the test (Odds Ratio [OR] = $7,752,95 \%$ Confidence Interval $[\mathrm{Cl}]=0.244-1.135)$, Barriers Subscale scores (Odds Ratio [OR] $=1.053,95 \%$ Confidence Interval $[\mathrm{Cl}]=1.015-1.092$ ), and Self-Efficacy scores (Odds Ratio $[\mathrm{OR}]=0.951,95 \%$ Confidence Interval $[\mathrm{Cl}]=0.919-$ $0.004)$. The regression analysis showed that living in a village/district, having a family/friends not having the test, and Barriers Subscale score, and Self-Efficacy score increased the risk of not having the test $0.412,7,752,1.053$, and 0.951 times, respectively (Table 3 ).

Table 3. Logistic Regression Analysis of the Risk Factors Causing the Barriers to having a Pap Smear Test

\begin{tabular}{|c|c|c|c|c|c|c|}
\hline \multirow{2}{*}{$\begin{array}{l}\text { Risk factors causing } \\
\text { the barriers to } \\
\text { having a Pap smear } \\
\text { test }\end{array}$} & \multirow[b]{2}{*}{ B } & \multirow[b]{2}{*}{ SE } & \multirow{2}{*}{$\begin{array}{l}\text { Odds Ratio } \\
\text { (OR) }\end{array}$} & \multicolumn{2}{|c|}{$\% 95 \mathrm{Cl}$} & \multirow[b]{2}{*}{$P$} \\
\hline & & & & Low & High & \\
\hline $\begin{array}{l}\text { Place of residence } \\
\text { Village/district (Ref) } \\
\text { City }\end{array}$ & -0.887 & 0.304 & 0.412 & 0.227 & 0.747 & 0.004 \\
\hline $\begin{array}{l}\text { Having a family/ } \\
\text { friends not having } \\
\text { the test } \\
\text { Yes (Ref) } \\
\text { No }\end{array}$ & 2.048 & 0.980 & 7,752 & 0.244 & 1.135 & 0.037 \\
\hline $\begin{array}{l}\text { The Health Belief } \\
\text { Model Scale for } \\
\text { Cervical Cancer and } \\
\text { the Pap Smear Test } \\
\text { - Barriers Subscale }\end{array}$ & 0.052 & 0.019 & 1.053 & 1.015 & 1.092 & 0.006 \\
\hline $\begin{array}{l}\text { The Self-Efficacy } \\
\text { Scale }\end{array}$ & -0.050 & 0.018 & 0.951 & 0.919 & 0.984 & 0.004 \\
\hline
\end{tabular}

* Only significant variables as a result of regression analysis are presented in Table 3. Other variables in regression analysis model are presented in the Methods section.

\section{DISCUSSION}

The current investigation evaluated barriers in the cervical cancer screening continuum through assessment of selfconceived obstacles for obtaining Pap smear tests. Almost half of the women (47.6\%) had a Pap smear test once in their lifetime. In the previous 12 months, almost a quarter of the women (24.8\%) had a Pap smear test at least once. In a study conducted in New Jersey and Southeast Pennsylvania, out of 705 women, $62 \%-73 \%$ were found to have had the Pap smear test once in their lifetime (20). In another study, 79\% of the women in an age range of 40-64 years were found to have had a Pap smear test one in the previous 3 years (21). In Turkey, in three different studies conducted in different groups from different regions, these ratios were reported to be $13.5 \%, 25.2 \%$, and $66.1 \%$, respectively $(6,7,14)$. Considering that Cancer Early Diagnosis Screening and Training Centres (KETEMs) provide screening service free of charge, these rates are expected to be substantively higher. However, the low rate of having a Pap smear test found in this study is in parallel with the results of previous national reports $(6,14)$. However, in several previous reports, it has been stated because of having no health insurance or a low socio-economic status, women could not join the screening programs (22) and medical costs have been reported to be barrier to not having the Pap smear test (23). In a metaanalysis study, poverty was reported to be a strong indicator of screening, diagnosis, treatment, and survival rates (24). However, the present results show that poverty is not the only barrier, and the women's educational level, family characteristics, working status, place of residence, number of children, and age are other barriers. Furthermore, the cultural structure of the society in which the women live should be considered as an integral part, and thereby, their awareness should be raised accordingly.

In the present study, $61.4 \%$ of the women were at least high school graduates and the rate of having a Pap smear test was substantially lower in this group. However, Watts et al. (25) reported that the women with at least a high school educational status (56\%) had a higher rate of having a Pap smear test. Several other investigations have shown that low levels of education are reliable indicators for screening non-adherence $(14,26)$. It is considered that the women did not allocate time for the Pap smear test because they were young and they had work- or family-related responsibilities. However, public health nurses and midwives have a great responsibility in raising these women's awareness regarding the Pap smear test.

It was also observed that some cultural characteristics constitute barriers to having a Pap smear test. Women in the present study did not have a Pap smear test because they did not know the symptoms and indicators of cervical cancer, believed that cervical cancer cannot be treated, had the fear of having a vaginal infection after the test, did not get permission from their husbands to have the test, because their family/close friends did not have it, and thought that the Pap smear test is embarrassing. In previous studies, cultural and social barriers included embarrassment to tell people about cervical cancer screening, husband and family not allowing screening, and not knowing what other people would think. This is consistent with other findings from previous studies, where women avoided screening due to attitudes of fear, lack of knowledge, inaccessibility of health services, cultural beliefs, and the belief that cervical cancer is an incurable disease $(15,27)$.

Living in a village/district (Odds Ratio [OR] $=0.412,95 \%$ Confidence Interval $[\mathrm{Cl}]=0.227-0.747$ ) was found to be a risk factor for not having a Pap smear test Similarly, those who have better access to a health center or living in city centers were found to have the test more $(8,28)$. Fernandez et al. (29) also reported that limited access to health centers is an important contributing factor in barriers to having a Pap smear test. Because health centers are not within walking distance in countryside, there is limited mass transportation opportunities, and those living in such areas have low income level, family practitioners and nurses need to provide mobile health services for these women to have a Pap smear test. 
In the present study, families and friends play an important role in encouraging the women to have the test. The fact that the women did not have a Pap smear test because their family members/friends did not have it (Odds Ratio [OR] $=7.752$, 95\% Confidence Interval $[\mathrm{Cl}]=0.244-1.135$ ) was found to be a risk factor. Women receive recommendations and advices from family members and friends and they receive information from the people they trust, which was found to be one of the important facilitators of Pap smear test. Similarly, it was found that women are informed by their friends or they consult their friends for an advice (30.9\%), and they are influenced by their family members or friends (\%22) $(30,31)$. This outcome highlights the importance of conventional communication channels or information sources, and also the information provided by family members and friends raises the women's self-efficacy levels.

The Health Belief Model Scale for Cervical Cancer and the Pap Smear Test - Barriers Subscale outcomes were found to be a contributing risk factor in barriers to having a Pap smear test for cervical cancer screening. Regression analysis showed that the total score of the Barriers Subscale total scores affect the women's having a Pap smear test 1.053 times (Odds Ratio $[\mathrm{OR}]=1.053,95 \%$ Confidence Interval $[\mathrm{Cl}]=1.015-$ 1.092). In a previous similar study in which barriers to having a Pap smear test were investigated, the Health Belief Model Scale for Cervical Cancer and the Pap Smear Test - Barriers Subscale scores were found to inhibit the women from having the test 0.22 times (32). Consistent with previous studies, our finding showed that women with higher scores on the perceived barriers for cervical cancer screening were less likely to have a Pap smear test ever than those with lower scores $(26,33)$. Development and application of education programs based on the Health Belief Model may raise the women's consciousness and reduce the barriers perceived, which may result in an increase in the rates of having a Pap smear test.

Another risk factor for having a Pap smear test is the SelfEfficacy Scale. Logistic regression analysis showed that SelfEfficacy Scale total scores influence the rate of having a Pap smear test 0.951 times (Odds Ratio [OR] $=0.951,95 \%$ Confidence Interval $[\mathrm{Cl}]=0.919-0.984)$. In a study investigating the Korean women's having a Pap smear test, a positive correlation was found between Self-Efficacy scores and the rate of having the test (34). Moreover, Fang et al. (20) found a positive correlation between Self-Efficacy results and the rate of having a Pap smear screening test, and Hogenmiller et al. (35) reported that self-efficacy was the primary indicator in having a Pap smear test.

\subsection{Limitations}

The present study has some limitations. The present study involved women from a few family health centers from city centers only. The results cannot be generalized to the general public, and especially those who do not visit these FHCs may have different barriers. Therefore, the results of this study should be interpreted with caution. The analysis was based on cross-sectional data; thus, causal relationships could not be inferred. The perception of barriers is self-reported, and it is difficult to measure the validity of these responses. On the other hand, one of the strengths of the study is that, it presents a comprehensive account of the barriers to having a Pap smear test, information about knowledge resources, and the women's perception.

\section{CONCLUSION}

The present study attempted to identify the barriers to women's having a Pap smear test and related risk factors. Almost half of the women (47.6\%) in the present study had a Pap smear test once in their life time. Living in a village/nonmetropolitan district, having family members/friends not having the test, higher Barriers Subscale scores, and lower Self-Efficacy scores were found to be barriers to having a Pap smear test. In addition, not knowing the symptoms of cervical cancer, believing that cervical cancer is not a treatable disease, thinking that having the test would cause a vaginal infection, not being able to get permission from husband, and thinking that the test is embarrassing were also found to be barriers to having the test. Based on the results of the present study, a well-designed health educational program regarding cervical cancer and the benefits of screening would raise awareness especially among the women with higher education in Turkey. To this end, a multimedia approach enriched with audio-visual materials and presented via personalized communication methods may result in positive results. Public health nurses should provide culturallyoriented health education, mobile health services should be offered for better accessibility to health services, routine Pap smear test health educations should be offered in hospitals, and individualized health education and consultancy should be provided.

\section{REFERENCES}

[1] McGuire S. World cancer report 2014. Geneva, Switzerland: World Health Organization, international agency for research on cancer, WHO Press, 2015. https://doi.org/10.3945/ an.116.012211. Cited: 20 May 2019.

[2] Stewart BWKP, Wild CP. World cancer report 2014. Public Health. http://publichealthwell.ie. Cited: 21 April 2019.

[3] Turkish Public Health Institution (TPHI). Cancer statistics Turkey, 2018. https://hsgm.saglik.gov.tr/depo/birimler/ kanser-db/istatistik/Turkiye_Kanser__Istatistikleri_2015.pdf. Cited: 24 March 2019.

[4] Turkish Statistical Institute (TSI). Health survey, 2012. http:// www.tuik.gov.tr/IcerikGetir.do?istab_id=223. Cited: 15 May 2019.

[5] Republic of Turkey, Ministry of Health Statistics. Annual Part 3: Morbidity, 2016. https://dosyasb.saglik.gov.tr. Cited: 15 May 2019.

[6] Kög I, Turan T, Karabük E, Karayünlü B, Özgül N, Demir ÖF, Gökçin H, Yeşiltepe C, Köse MF. Cervical and breast cancer screening programme results of Etlik KETEM Group. TAF Preventive Medicine Bulletin 2012;11(2):145-152 (In Turkish). 
[7] Solt A, Dutucu N, Gunaydin S, Citil ET, Arik E. Evaluation of the Pap smear test status of women and affecting factors. Int J Caring Sci 2018;11(2):1231-1238.

[8] Crawford A, Benard V, King J, Thomas CC. Peer reviewed: understanding barriers to cervical cancer screening in women with access to care, behavioral risk factor surveillance system, 2014. Prev Chronic Dis 2016:13: E154.

[9] Modibbo FI, Dareng E, Bamisaye P, Jedy-Agba E, Adewole A, Oyeneyin L, Olayinka O, Adebamowo, C. Qualitative study of barriers to cervical cancer screening among Nigerian women. BMJ open 2016;6(1): e008533.

[10] Racey CS, Gesink DC. Barriers and facilitators to cervical cancer screening among women in rural Ontario, Canada: The role of self-collected HPV testing. J Rural Health 2016;32(2):136-145.

[11] Akinlotan M, Bolin JN, Helduser J, Ojinnaka C, Lichorad A, McClellan D. Cervical cancer screening barriers and risk factor knowledge among uninsured women. J Community Health 2017;42(4):770-778.

[12] Soper DS. A-priori sample size calculator for multiple regression, 2019. [Software]. http://www.danielsoper.com/ statcalc. Cited: 15 May 2019.

[13] Cohen J, Cohen P, West SG, Aiken LS. Applied multiple regression/correlation analysis for the behavioral sciences (3rd edition). 2003. Mahwah, NJ: Lawrence Earlbaum Associates.

[14] Kurt G, Akyuz A. Evaluating the effectiveness of interventions on increasing participation in cervical cancer screening. JNR 2019;0(0):1-11.

[15] Salem MR, Amin TT, Alhulaybi AA, Althafar AS, Abdelhai RA. Perceived risk of cervical cancer and barriers to screening among secondary school female teachers in Al Hassa, Saudi Arabia. APJCP 2017;18(4):969.

[16] Lechner L, De Vries H, Offermans N. Participation in a breast cancer screening program: influence of past behavior and determinants on future screening participation. Prev Med 1997;26(4):473-482.

[17] Beser A, Bahar Z, Aydogdu NG, Ersin F, Kissal A. Validity and reliability study for the self-efficacy scale. HealthMED 2012;195-200.

[18] Guvenc G, Akyuz A, Açikel CH. Health belief model scale for cervical cancer and Pap smear test: psychometric testing. JAN 2011;67(2):428-437.

[19] Tabachnick BG, Fidell LS. Using multivariate statistics (sixth ed.). Pearson, Boston, 2013.

[20] Fang CY, Ma GX, Tan Y, Chi N. A multifaceted intervention to increase cervical cancer screening among underserved Korean women. Cancer Epidemiol Biomarkers Prev 2007;16(6):12981302.

[21] Lee EE, Eun Y, Lee SY, Nandy K. Age-related differences in health beliefs regarding cervical cancer screening among Korean American women. J Transcult Nurs 2012;23(3):237-245.
[22] Bazargan M, Bazargan SH, Farooq M, Baker RS. Correlates of cervical cancer screening among underserved Hispanic and African-American women. Prev Med 2004;39(3):465-473.

[23] Adams EK, Breen N, Joski PJ. Impact of the national breast and cervical cancer early detection program on mammography and Pap test utilization among white, Hispanic, and African American women: 1996-2000. Cancer 2007;109(S2):348-358.

[24] Newmann SJ, Garner EO. Social inequities along the cervical cancer continuum: a structured review. Cancer Causes Control \& Control 2005;16(1):63-70.

[25] Watts L, Joseph N, Velazquez A, Gonzalez M, Munro E, Muzikansky A, Rauh-Hain JA, del Carmen, MG. Understanding barriers to cervical cancer screening among Hispanic women. AJOG 2009;201(2):199-e1.

[26] del Carmen MG, Findley M, Muzikansky A, Roche $M$, Verill $\mathrm{CL}$, Horowitz N, Seiden MV. Demographic, risk factor, and knowledge differences between Latinas and non-Latinas referred to colposcopy. Gynecol Oncol 2007;104(1):70-76.

[27] Daley E, Perrin K, Vamos C, Hernandez N, Anstey E, Baker E, Kolar S, Ebbert, J. Confusion about Pap smears: lack of knowledge among high-risk women. J Womens Health 2013;22(1):67-74.

[28] Ebu NI, Mupepi SC, Siakwa MP, Sampselle CM. Knowledge, practice, and barriers toward cervical cancer screening in Elmina, Southern Ghana. Int J Womens Health 2015;7:31-39.

[29] Fernández ME, Diamond PM, Rakowski W, Gonzales A, Tortolero-Luna G, Williams J, Morales-Campos, DY. Development and validation of a cervical cancer screening self-efficacy scale for low-income Mexican American women. Cancer Epidemiol Biomarkers Prev 2009;18(3):866875.

[30] Ezem BU. Awareness and uptake of cervical cancer screening in Owerri, South-Eastern Nigeria. Ann Afr Med 2007;6(3):94.

[31] Ogunwale AN, Sangi-Haghpeykar H, Montealegre J, Cui Y, Jibaja-Weiss M, Anderson ML. Non-utilization of the Pap test among women with frequent health system contact. J Immigr Minor Health 2016;18(6):1404-1412.

[32] Karimy $M$, Azarpira $H$, Araban $M$. Using health belief model constructs to examine differences in adherence to Pap test recommendations among Iranian women. APJCP 2017;18(5):1389.

[33] Tahmasebi R, Hosseini F, Noroozi A. The effect of education based on the health belief model on women's practice about Pap smear test. HAYAT 2016;21(4):80-92.

[34] Park S, Chang S, Chung, C. Effects of a cognition-emotion focused program to increase public participation in Papanicolaou smear screening. PHN 2005;22(4):289-298.

[35] Hogenmiller JR, Atwood JR, Lindsey AM, Johnson DR, Hertzog M, Scott Jr JC. Self-efficacy scale for Pap smear screening participation in sheltered women. Nurs Res 2007;56(6):369377. 